\title{
Correlation Between the Oral Manifestations of Rheumatoid Arthritis Patients on Different Treatments with The Clinical Disease Activity
}

\author{
Atika M. Alahmed ${ }^{1}$, Kassim F.Abdulkareem $^{2}$,Taghreed F. Zaidan ${ }^{1}$, \\ Assaad Yahya ${ }^{3}$ \\ ${ }^{1}$ (Department Of Oral Diagnosis, Faculty Of Dentistry, UniversityOf Baghdad, Iraq) \\ ${ }^{2}$ (Department Of Clinical Pathology, Faculty Of Pharmacy, University Of Basrah, Iraq) \\ ${ }^{3}$ (Department Of Biotechnology\& Genetics, Faculty Of Agriculture, University Of Basrah, Iraq)
}

\begin{abstract}
:
Objective:Toevaluate the oral findings and correlating the oral findings with the clinical disease activity index. Subjects, Materials and Methods:This cross- sectional studyincludedeighty-five rheumatoid arthritis patients. Twenty-five patients were on Methotrexate, thirty patients on Etanercept and thirty patients were on a combination of Methotrexate and Etanercept. Each patient was examined to calculate the clinical disease activity index and to detect any oral finding.

Results: The highest summation of rheumatoid arthritis patients was presented with a high clinical disease activity index, while the number of those with low disease activity index was the lowest. Oral dryness showed to be the most common oral findings (60\%) followed by tempromandibular joint disorders (31.8\%) then aphthous ulcerations (9.4\%) and glossitis (5.8\%), while the lichenoid drug reaction, angular chelitis and geographic tongue were the less commonly seen findings (1.1\% for each). Most of the oral findings were seen in patients treated with Etanercept or Methotrexate alone, while the patients treated with a combination of them had less oral side effects. A higher number of rheumatoid arthritis patients with oral findings were showing high and moderate disease activity.

Conclusions: The oral dryness, tempromandibular joint disorders and aphthous ulcerations were the main oral manifestations found in rheumatoid arthritis patients. Angular chelitis positively correlate with the increasing in the clinical disease activity.
\end{abstract}

Keywords:Rheumatoid arthritis, Oral findings, Clinical disease activity index.

\section{Introduction}

Rheumatoid arthritis (RA) is an autoimmune disease characterized by its chronic pattern, the genetic susceptibility is essential in this disease along with multiple non genetic factors such as hormonal factors, smoking, infections. RA affects any age with female predilection. [1]. The small joints of the bodyare the commonly affected joints (symmetrically) predominantly those of the hands, elbow and knees while the last joints to be involved are the cervical spine, tempromandibular (TMJ) and sternoclavicular joints. Besides these articular manifestations, RA has many other extra articular outcomes, including those seen in the skin, oral cavity, cardiovascular system, lungs and hematological outcomes [2].

RA reveals different grades of clinical activity which can be evaluated via multiple scores by using several measures to judge the activity. Example of those measures:the counting of swollen / tender joints, the patient's/physician's assessment of the disease and laboratory estimation of at least one of the acute-phase reactant [3].

The oral manifestations are considered as an important extra articular outcome of this disease as well as a distinct side effect of the drugs used in RA treatment, those comprising set of features like periodontitis, xerostomia, ulcerations, TMJ disorders, candidal infection and many other features[4].

\section{II.Subjects, Materials and Methods}

This study includes eighty- five patientsattending the Rheumatology center/Baghdad teaching hospital who werediagnosed by the rheumatologist according to the American College of Rheumatology (ACR) Classification Criteria for RA [5], they were free to accept or refuse the participation(by signing a written consent form). Twenty five patients were taking Methotrexate(MTX) and folic acid, thirty patients were taking Etanercept (Etan)and the last thirty patients were taking a combination of them. The patients with other autoimmune disease, those who were smoking or drinking alcohol and patients had previous head and neck radiation were excluded. 
The clinical disease activity index(CDAI) for each patient was calculated by counting each tender and swollen joint (joints of the hand, the wrist, elbows, shoulders and knees) and then by adding the numbers of the patient's/physician's visual analogue scale of $1-10 \mathrm{~cm}$, the results are recorded with the other baseline information.

A thorough oral examination with disposable instruments was done starting from the lips, cheeks, upper and lower sulci ending with an examination of the TMJ and the associated muscles, the patients were also asked if theyexperienced any oral dryness or abnormal taste.

\section{III.Results}

Demographic findings:The mean numbers of the age were (41.3, 42.5 and 44) for the MTX, Etan and combination groups, respectively, with the female being the largest part of the study sample (89.4\%). The results showed no significant difference in the means of age among the 3 studied groups, and there was no significant difference in the gender distribution as well (as in Table 1). Therefore; the sociodemographic variables were unlikely to confound any detected variances between cases and controls.

\begin{tabular}{|c|c|c|c|c|c|c|c|}
\hline \multicolumn{3}{|c|}{ Variables } & \multirow{2}{*}{$\begin{array}{r}\begin{array}{r}\text { Etanrcept } \\
\mathbf{n}=\mathbf{3 0}\end{array} \\
42.5 \pm 7.7\end{array}$} & \multirow{2}{*}{$\begin{array}{l}\begin{array}{l}\text { Methotrexat } \\
\text { e }\end{array} \\
\quad \mathbf{n = 2 5} \\
41.3 \pm 8.2\end{array}$} & \multirow{2}{*}{$\begin{array}{c}\begin{array}{c}\text { Combnation } \\
\mathbf{n}=\mathbf{3 0}\end{array} \\
44 \pm 7.6\end{array}$} & \multirow{2}{*}{$\begin{array}{r}\begin{array}{r}\text { Total } \\
\mathbf{n}=\mathbf{8 5}\end{array} \\
42.6 \pm 7.6\end{array}$} & \multirow{2}{*}{\begin{tabular}{|c} 
P value \\
$0.167 \mathrm{a}$
\end{tabular}} \\
\hline $\begin{array}{l}\text { Age } \\
\text { (years) }\end{array}$ & Mean \pm & & & & & & \\
\hline \multirow{4}{*}{ Gender } & \multirow[t]{2}{*}{ Female } & No. & 26 & 23 & 27 & 76 & \multirow[t]{4}{*}{$0.341 \mathbf{b}$} \\
\hline & & $\%$ & $86.7 \%$ & $92.0 \%$ & $90.0 \%$ & $89.4 \%$ & \\
\hline & \multirow[t]{2}{*}{ Male } & No. & 4 & 2 & 3 & 9 & \\
\hline & & $\%$ & $13.3 \%$ & $8.0 \%$ & $10.0 \%$ & $10.5 \%$ & \\
\hline
\end{tabular}

a: - Non significant $(\mathrm{P}>0.05)$ by one way ANOVA, b: - Chi square test

Clinical disease activity index(CDAI): The clinical disease activity index (CDAI) was calculated for each patient in the three groups for assessing the degree of the disease activity, the results of CDAI followed a normal distribution, so that, the mean \pm standard deviation of this index were taken. The index was further categorized into 3 arms of activity where 2.8-10 represented low activity, 10-22 represented moderate activity and $>22$ represented high activity.

After mean and standard deviation calculation, the results showed that the highest mean of CDAI (27.2) was seen in the MTX group and the lowest mean (19.8) was seen in the combination group, while that of the Etan was $(20.4 \%)$, the results also showed that the number(percentage) of RA patients on Etan with low CDAI was $5(16.7 \%)$, with moderate CDAI $12(40 \%)$ and with high CDAI was $13(4.3 \%)$. Regarding the RA patients on MTX, no patient had low CDAI, the number (percentage) of patients with moderate CDAI was $9(36 \%)$ and with high CDAI was $16(64 \%)$. For RA patients on combination, the number (percentage) of low CDAI was $6(20 \%)$, with moderate CDAI was $13(43.3 \%)$ and with high CDAI was $11(36.7 \%)$ as seen in (Table 2$)$.

\begin{tabular}{|c|c|c|c|c|c|c|c|}
\hline \multicolumn{3}{|c|}{ Variables } & Etanercept & Methotrexat & Combination & Total & $\mathrm{P}$ value \\
\hline \multicolumn{3}{|c|}{$\begin{array}{l}\mathrm{CADI} \\
(\text { mean } \pm \mathrm{SD})\end{array}$} & $20.4 \pm 10.1$ & $27.2 \pm 12.6$ & $19.8 \pm 8.7$ & $\begin{array}{l}22.2 \pm \\
10.9\end{array}$ & $0.327 \mathrm{a}$ \\
\hline \multirow{6}{*}{ CADI } & \multirow[t]{2}{*}{ Low } & No. & 5 & 0 & 6 & 11 & \multirow{6}{*}{$0.126 \mathrm{~b}$} \\
\hline & & $\%$ & $16.7 \%$ & $0.0 \%$ & $20.0 \%$ & $12.9 \%$ & \\
\hline & \multirow[t]{2}{*}{ Moderate } & No. & 12 & 9 & 13 & 34 & \\
\hline & & $\%$ & $40.0 \%$ & $36.0 \%$ & $43.3 \%$ & $40 \%$ & \\
\hline & \multirow[t]{2}{*}{ High } & No. & 13 & 16 & 11 & 40 & \\
\hline & & $\%$ & $43.3 \%$ & $64.0 \%$ & $36.7 \%$ & $47 \%$ & \\
\hline
\end{tabular}

a:- one way ANOVA, b:- chi -square test.

Oral Findings:All participants in this study were examined looking for any oral finding like ulcerations, gingivitis and salivary gland swelling. We also looked for any abnormal symptoms like oral dryness and TMJ disorders.

The number (percentage) of the patients who didn't show any oral findings was $26(30 \%)$, the other RA patients had different manifestations as shown in (Table 3). The main oral findings were the dry mouth 51 patients $(60 \%)$, followed by TMJ disorders(TMJ pain, clicking, limitation in the mouth opening and joint stiffness) in 27 patients(31\%) then aphthous ulcerations in 8 patients(9.4\%) and glossitis in 5 patients $(5.8 \%)$. While the other less frequently seen findings were one case of lichenoid drug reaction $(3.3 \%)$, one case of angular chelitis and geographic tongue $(3.3 \%)$ for each. 
Correlation Between The Oral Manifestations Of Rheumatoid Arthritis Patients On Different...

\begin{tabular}{|c|c|c|c|c|c|}
\hline \multicolumn{2}{|c|}{ Variables } & Etanercept & Methotrexate & Combination & Total \\
\hline \multicolumn{2}{|c|}{ Number } & 30 & 25 & 30 & 85 \\
\hline \multirow[t]{2}{*}{ Dry Mouth } & No. & 20 & 15 & 16 & 51 \\
\hline & $\%$ & $66.7 \%$ & $60.0 \%$ & $53.3 \%$ & $60.0 \%$ \\
\hline \multirow[t]{2}{*}{ TMJ disorders } & No. & 6 & 11 & 10 & 27 \\
\hline & $\%$ & $20.0 \%$ & $44.0 \%$ & $33.3 \%$ & $31.8 \%$ \\
\hline \multirow[t]{2}{*}{ Lichenoid drug reaction } & No. & 0 & 0 & 1 & 1 \\
\hline & $\%$ & 0 & 0 & $3.3 \%$ & $1.1 \%$ \\
\hline \multirow[t]{2}{*}{ Geographic tongue } & No. & 0 & 0 & 1 & 1 \\
\hline & $\%$ & 0 & 0 & $3.3 \%$ & $1.1 \%$ \\
\hline \multirow[t]{2}{*}{ Angular chelitis } & No. & 0 & 0 & 1 & 1 \\
\hline & $\%$ & 0 & 0 & $3.3 \%$ & $1.1 \%$ \\
\hline \multirow[t]{2}{*}{ Glossitis } & No. & 2 & 2 & 1 & 5 \\
\hline & $\%$ & $6.6 \%$ & $8 \%$ & $3.3 \%$ & $5.8 \%$ \\
\hline \multirow[t]{2}{*}{ Aphthous ulcerations } & No. & 2 & 4 & 2 & 8 \\
\hline & $\%$ & $6.6 \%$ & $16 \%$ & $6.6 \%$ & $9.4 \%$ \\
\hline
\end{tabular}

In the Etanercept group, the result showed that the main oral finding was the dry mouth in $20(66.7 \%)$ patients followed by TMJ disorders in $6(20 \%)$ patients then glossitis in $2(6.6 \%)$ patients and aphthous ulcerations in $2(6.6 \%)$ patients.

In the Methotrexate group, the dry mouth shown in 15(60\%) patients, TMJ disorders found in 11 $(44 \%)$ patients followed by aphthous ulcerations in $4(16 \%)$ patients and glossitis in $2(8 \%)$ patients.

In the group of combination, $16(53.3 \%)$ of them had dry mouth, 10(33.3\%) patients had TMJ disorders, 2(6.6\%) patients were having aphthous ulcerations and one patient(3.3) had glossitis. Only in this group one case $(3.3 \%)$ with lichenoid drug reaction (figure $3-1 \mathrm{a})$, one case $(3.3 \%)$ of the angular chelitis (figure $3-1 \mathrm{~b}$ ) and one case (3.3\%) of geographic tongue(figure 3-1d\&e) were found.
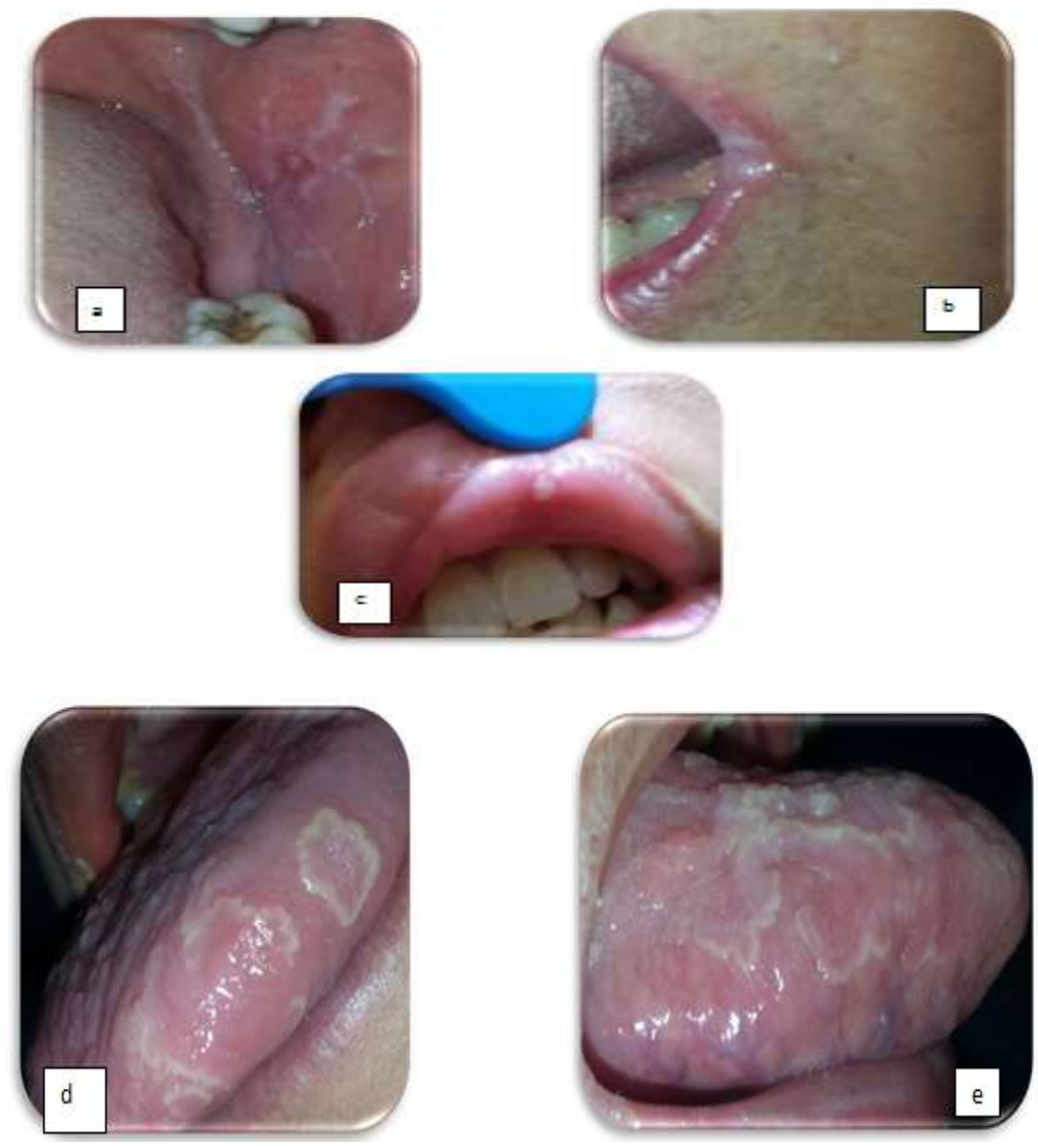

Figure (1): Some of the Oral Findings in RA patients, a: Lichenoid reaction b: Angular chelitis c: Apthous ulceration d\&e: Geographic tongue. 
Oral findings in relation to CDAI:The distribution of the oral findings in relation to the of clinical activity revealed that the higher numbers of patients with oral findings were showing high activity of the disease clinically where 24 of the patients with oral dryness, 13 of the patients with TMJ disorders, 1 patient with lichenoid drug reaction, 3 patients with glossitis and 6 patients with aphthous ulcerations were under this subclass.

While the least numbers of the patients were showing low disease activity clinically where 5 patients with dryness, 1 patients with TMJ disorders and 1 patient with angular chelitis were under this subclass as shown in (Table 4).

\begin{tabular}{|c|c|c|c|c|c|}
\hline Variable & & Low CDAI & Moderate CDAI & High CDAI & P-valuea \\
\hline Dry mouth & $\begin{array}{l}\text { No } \\
\%\end{array}$ & $\begin{array}{c}5 \\
45 \%\end{array}$ & $\begin{array}{c}22 \\
64.7 \%\end{array}$ & $\begin{array}{c}24 \\
60 . \%\end{array}$ & 0.526 \\
\hline TMJ disorders & $\begin{array}{l}\text { No. } \\
\%\end{array}$ & $\begin{array}{c}1 \\
9.1 \%\end{array}$ & $\begin{array}{c}13 \\
38.2 \%\end{array}$ & $\begin{array}{c}13 \\
32.5 \%\end{array}$ & 0.194 \\
\hline Lichenoid drug reaction & $\begin{array}{c}\text { No. } \\
\%\end{array}$ & $\begin{array}{l}0 \\
-\end{array}$ & $\begin{array}{l}0 \\
-\end{array}$ & $\begin{array}{c}1 \\
2.5 \%\end{array}$ & 0.581 \\
\hline Angular chelitis & $\begin{array}{l}\text { No. } \\
\%\end{array}$ & $\begin{array}{c}1 \\
9.1 \%\end{array}$ & $\begin{array}{l}0 \\
-\end{array}$ & $\begin{array}{l}0 \\
-\end{array}$ & $0.046 \mathrm{~b}$ \\
\hline Geographic tongue & $\begin{array}{l}\text { No. } \\
\%\end{array}$ & $\begin{array}{l}0 \\
-\end{array}$ & $\begin{array}{c}1 \\
2.9 \%\end{array}$ & $\begin{array}{l}0 \\
-\end{array}$ & 0.433 \\
\hline Glossitis & $\begin{array}{l}\text { No. } \\
\%\end{array}$ & $\begin{array}{l}0 \\
-\end{array}$ & $\begin{array}{c}2 \\
5.9 \%\end{array}$ & $\begin{array}{c}3 \\
7.5 \%\end{array}$ & 0.634 \\
\hline Aphthous ulcerations & $\begin{array}{l}\text { No. } \\
\%\end{array}$ & $\begin{array}{l}0 \\
-\end{array}$ & $\begin{array}{c}2 \\
5.9 \%\end{array}$ & $\begin{array}{c}6 \\
15 \%\end{array}$ & 0.231 \\
\hline
\end{tabular}

a:- Chi-square test. b:- Significant difference $(\mathrm{P}<0.05)$.

\section{IV.Discussion}

Demographic data: In the present study, the RA patients age ranged from 30 to 50 years with mean age was (42.6) years, this matches the mean age in the study of (Ramos-Remus et al., 2002) [6].The total number of the female patients was $76(89.4 \%)$ which is higher than the total number of males, which was 9 $(10.6 \%)$, this resembles the gender distribution in other studies $[2,4,7]$.

Clinical disease activity index (CDAI): Rheumatoid arthritis involves the inflammation of the joints with ubsequent destruction and impaired function, therefore; it is important to assess the extent of the activity of RA clinically to measure the improvement, response to the present therapies and the necessity of moving to other drugs [8].

The results showed that the higher mean of the CDAI was in the MTX group (27.2) and lower mean found in the combination group (19.8). On the other hand, the number of RA patients in Etan group with high CDAI was (13) versus (16) patients in the MTX group, while the number of RA patients with low CDAI in Etan group was (5) versus (0) patients in the MTX group, this match the findings in the study of [9,10], they both stated that Etan alone was safer, more tolerated and showed better improvement of the disease activity and radiographic changes (bone erosions and reduced jot space) than MTX alone.

The results also showed that the number of patients in the combination group with low CDAI was (6) and with high CDAI was (11), this better CDAI result in the combination group matched the results of [11,12] who revealed that combining MTX with Etan showed better outcomes regarding the CDAI, disease progression and joints damage.

Oral Findings: As with any chemical compound, the drugs used to treat RA patients usually have multiple side effects including oral side effects. The results showed that oral dryness was the most frequent oral finding followed by TMJ disorders, then aphthous ulcerations and glossitis, with less frequently seen findings, which were the lichenoid drug reaction, geographic tongue and angular chelitis.

\section{1- Oral dryness}

Oral dryness (xerostomia) differs from hyposalivation because the latter description is associated with decreased salivary flow rate $(<0.1 \mathrm{ml} / \mathrm{min})$, this annoying feeling may be seen in about $40 \%$ of the elderly people[13].

The results revealed that the main oral finding in RA patients in the present study was the oral dryness (in $60 \%$ of all RA patients), the patients mentioned a feeling of dryness associated with cracked lips, difficulty in swallowing and speech, the mucosa appeared dry and stick to the gloves during smear taking, usually they answer (NO) regarding the eye dryness.

The frequency of dry mouth among the RA groups was distributed with simple differences which may not give a clear clue whether this symptom is because they were predominantly females [14] or caused by the 
drugs that usually used to treat RA [4,9] or it may be originally related to the disease itself as the inflammatory cytokiens in RA, especially TNF-a which plays an important role in the salivary gland damage and Sjögren's syndrome (SS) pathogenesis [15]. Koskiet al., in 2004 [16] also stated that an increased expression of TNF-a was found in the labial cells taken from SS patients, so that, TNF-a mediated salivary gland destruction may be present causing different degrees of dryness but not necessarily SS.

\section{2- Tempromandibular Joint Disorders}

Although the TMJ is one of the joints that affected lately by RA, but TMJ disorders can be seen in about half of the RA patients [17], of these disorders, joint pain that may radiate to the head and the face and clicking were the most frequently seen in this study as well as joint stiffness with difficulty in movements. The inflammation that marks the pathophysiology of RA extend to TMJ just like the other joints and cause the damage to the cartilage, bone and synovial membrane [18].

The results revealed that TMJ disorders found in a percentage of $31.8 \%$ of RA patients this is close to what was found in the study of [19] who reported a $35.7 \%$ of TMJ disorders.

\section{3 - Oral Lichenoid Drug Reaction}

Oral lichenoid drug reaction is usually similar to the lichen planus clinically as well as in the histopathological view, its eruption correlates with the administration of the offending drug, several drugs were reported to cause this eruption such as anti hypertensive, gold, antimalarials and oral hypoglycemic drug [20]. In the present study, a single case of lichenoid eruption $(1.1 \%)$ was seen in a female patient who re-used MTX after a period of discontinuation, the lesion was reticular in shape with white striae on the left side of her mouth. This matched with the first report of an oral lichenoid drug reaction due to low dose methotrexate in RA patients, which was by Jinbu et al., in 2015 [21], who reported an erythematous lesion with white striae because of MTX usage that did not respond to the treatment of steroid but diminished and showed an increased epithelialization after MTX termination and he also described a recurrence of this lesion with the re usage of MTX.

\section{4 - Geographic Tongue}

therapy. To our knowledge, this is the first study reports the presence of geographic tongue in RA patients. The causes of geographic tongue may be unknown or may be correlated to hormonal factors, psychological stress, vitamin B12 deficiency as well as its relation to different diseases like psoriasis and reactive arthritis [22].

\section{5 -Angular Chelitis}

In the present study, only one case $(1.1 \%)$ of angular chelitis was found in a female patient in the combination group, this agreed with Strangfeld and Listing in 2006 [23] who stated that candidal infections are less commonly seen in RA patients. The explanation of the occurrence of this event can be related to the iron or vitamin $\mathrm{B} 12$ depletion or due to the immune suppressive effect produced by anti-rheumatic drugs like the anti TNF-a drugs and MTX [4,24,25].

An interesting findings were found by Bishu et al., in 2014[26] who stated that despite the increased colonization of C.albicans in RA patients, but the anti fungal property in the saliva of RA patients was preserved. He also stated that the subclinical colonization of C.albicans may induce or aggravate the joint pathology and symptoms because of $\beta-1,3$-glucan, which is an antigen found in their cell wall which can increase the activity of RA clinically.

\section{6- Glossitis}

In the present study, The glossitis was found in 5 RA patients (5.8\%), this presentation may be explained by the possibility of anemia and nutritional deficiency, especially iron and vitamin B12 as they usually reported to cause atrophic and depapillated lingual mucosaor may be related to the increased frequency of oral dryness which decreased the washing and neutralizing action provided by saliva against any irritating agent, the glossitis can occur as a reaction to the drugs of these drugs, MTX was reported to cause glossitis and other mucosal lesions ranging from mild inflammation to moderate ulcerations in its low doses and sever mucositis in cases of high dose when used to treat malignancies Glossitis can be seen with different conditions such as nutritional deficiencies, oral dryness, systemic infections (syphilis), local (candidal, viral or bacterial) infections and as a reaction to medications, this inflammation resulting in erythematous, burning and swollen tongue in different degrees $[22,27,28,29]$. 


\section{7-Aphthous Ulcerations (AU)}

The results showed that $8(9.4 \%)$ of RA patients presented with AU, these ulcers were multiple tiny erythematous ulcers, distributing on the lips, palate and the posterior borders of the tongue. Two patients $(6.6 \%)$ in the Etan group and 2 patients (6.6\%) in the combination groups had AU, while RA patients in the MTX group showed 6 cases $(16 \%)$ of the $\mathrm{AU}$, these results are in line with the results of Bathonet al., in (2000) [9] who showed that the RA patients in the MTX group had (14\%) mouth ulcerations while RA patients in the Etan group (on 25mg/week) showed (5\%) mouth ulcerations. Genovese et al., (2002) [10] has reported a similar result with (17\%) mouth ulceration in RA patients using MTX compared to (7\%) mouth ulcerations in Etan treated RA patients.

The results in the present study regarding mouth ulceration disagreed with Pedrazas study in (2010)[4] in which he reported a higher number of oral lesions in the MTX group which was (60.7\%) but agreed with that study in the distribution of the oral lesions, where the tongue was one of the commonest sites(21.6\%) followed by the palate(18.9\%).

\section{Correlation Between Oral Findings And Cdai:}

The clinical disease activity index is an important mean to evaluate the degree of RA activity depending on the clinical presentation, it has good reliability and excellent validity [3]. CDAI have been assessed for each patient participate in this study, the mean of this index was calculated in each group, the results were (20.4, 27.2 and 19.8 for RA patients on Etan, MTX and those on combination, respectively).

Concerning the distribution of the oral findings in relation to CDAI, the largest number of patients with oral dryness were exhibiting high and moderate CDAI (24 patients and 22 patients, respectively), this matched what was shown byAbrão et al., in (2016) [30] who revealed that the risk of hyposalivation rises directly with the increasing in the severity of the disease.

The results also showed that the larger number of RA patients with TMJ disorders having a high CDAI (13 patients) and moderate CDAI (13 patients) this was consistent with Moen et al., (2005) [31] who related the salivary dysfunction and TMJ disorders to an increased disease activity.

Bishu et al.,in (2014) [26] stated that the presence of $\beta-1,3$-glucan, which is an antigen found in the candidal cell wall can increase the activity of RA clinically. This explained the statistical significance of the correlation between angular chelitis and CDAI ( $\mathrm{P}=0.046)$. Five RA patients presented with glossitis, (3) of them were having a high CDAI and (2) were having moderate disease activity. Similarly, (8) patients presented with $\mathrm{AU},(6)$ of them had high disease activity and (2) had moderate CDAI, therefore; the results revealed a higher number of RA patients with oral findings presented with moderate and high disease activity clinically.

\section{Conclusion}

The RA patients with higher CDAI presented with higher number of oral findings.The RA patients on a combination treatment of Etanercept and Methotrexate showed lower CDAI values and lower number of patients with oral findings.

\section{References}

[1]. Hayward, Kristen, and Carol A. Wallace. "Recent developments in anti-rheumatic drugs in pediatrics: treatment of juvenile idiopathic arthritis.",Arthritis research \& therapy2009; 11(1): 1.

[2]. Klippel H, Stone J, Crofford L, White P. "Primer on the Rheumatic Diseases". 13th edition. Springer. USA 2008; 114-140.

[3]. Felson D, Anderson J, Boers M, Bombardier C, Chernoff M, Fried B, Furst D, Goldsmith C, Kieszak S, Lightfoot R, Paulus H, Tugwell P, Weinblatt M, Widmark R, Williams H and Wolfe F. "The American college of Rheumatology preliminary core set of disease activity measures for rheumatoid arthritis clinical trials". Arthritis \& Rheumatism 1993; 36(6): 729-740.

[4]. Pedrazas C, Azevedo M, Torres S. "Oral events related to low-dose methotrexate in rheumatoid arthritis patients". Braz. oral res 2010; 24 (3): 368- 370.

[5]. Aletaha D, Neogi T, Silman A, Funovits J, Felson D, Bingham III C, Birnbaum N, Burmester G, Bykerk V, Cohen M, Combe B, Costenbader K, Dougados M, Emery P, Ferraccioli G, Hazes J, Hobbs K, Huizinga t, Kavanaugh A, Kay J, Kvien T, Laing T, Mease P, Ménard H, Moreland L, Naden R, Pincus T, Smolen J, Stanislawska-Biernat E, Symmons D, Tak P, Upchurch K, Vencovský J, Wolfe F, Hawker G. "Rheumatoid arthritis classification criteria: an American College of Rheumatology/European League against Rheumatism collaborative initiative". Ann Rheum Dis 2010; 69:1580-1588.

[6]. Ramos-Remus, C., Barragan, G., Avila, F., Lopez, F., Ramirez, F., Diaz, J., Bugarin, O., Aguilar, A., \& González, G."Genotoxicity assessment using micronuclei assay in rheumatoid arthritis patients". Clin Exp Rheumatol 2002; 20 (2): 12-208.

[7]. Pawłowska, J., Smoleńska, Z., Daca, A., Witkowski, J., \&Bryl, E. "Older age of rheumatoid arthritis onset is associated with a higher activation status of peripheral blood CD4+ T cells and disease activity". Clin Exp Immunol 2011; 163 (2): 157-164.

[8]. Aletaha, D., Ward, M., Machold, K., Nell, V., Stamm, T. \& Smolen, J. " Remission and active disease in rheumatoid arthritis: Defining criteria for disease activity states". Arth \& Rheu 2005; 52 (9): 2625-2636.

[9]. Van der Heijde D, Klareskog L, Rodriguez-Valverde V, Codreanu C, Bolosiu H, Melo-Gomes J, Tornero-Molina J, Wajdula J, Pedersen R and Fatenejad S."Comparison of etanercept and methotrexate, alone and combined, in the treatment of rheumatoid arthritis: two-year clinical and radiographic results from the TEMPO study, a double-blind, randomized trial”. Arth\& Rheum. 2006; 54(4):1063-74 
[10]. Bathon J.M, Martin R, Fleischmann R, Tesser J, Schiff M, Keystone E, Genovese M, Wasko M, Moreland L, Weaver A and Markenson J. "A comparison of etanercept and methotrexate in patients with early rheumatoid arthritis". New Eng Jour of Med. 2000; 343(22): 1586-1593.

[11]. Genovese M, Bathon J, Martin R, Fleischmann R, Tesser J, Schiff M, Keystone E, Wasko M, Moreland L, Weaver A and Markenson J. " Etanercept versus methotrexate in patients with early rheumatoid arthritis: two-year radiographic and clinical outcomes". Arth \& Rheum. 2002; 46(6): 1443-1450.

[12]. Klareskog, L., van der Heijde, D., de Jager, J., Gough, A., Kalden, J., Malaise, M., Mola, E., Pavelka, K., Sany, J., Settas, L., \& Wajdula, J. " The therapeutic effect of the combination of etanercept and methotrexate compared with each treatment alone in patients with rheumatoid arthritis: double-blind randomized controlled trial". The Lanc. 2004; 363(9410): 675-681.

[13]. Emery, P., Breedveld, F., Hall, S., Durez, P., Chang, D., Robertson, D., Singh, A., Pedersen, R., Koenig, A. \& Freundlich, B. “ Comparison of methotrexate monotherapy with a combination of methotrexate and etanercept in active, early, moderate to severe rheumatoid arthritis (COMET): a randomised, double-blind, parallel treatment trial”. The Lanc.2008; 372(9636): $375-382$.

[14]. Mortazavi H, Baharvand M, Movahhedian A, Mohammadi M and Khodadoustan A. "Xerostomia Due to Systemic Disease: A Review of 20 Conditions and Mechanisms". Ann Med Health Sci Res.2014; 4(4): 503-510.

[15]. Flink H, Bergdahl M, Tegelberg A, Rosenblad A and Lagerlöf F. "Prevalence of hyposalivation in relation to general health, body mass index and remaining teeth in different age groups of adults". Com dent and oral epid.2008; 36(6): 523-531.

[16]. Koski H, Janin A, Humphreys-Beher MG, Sorsa T, Malmström M and Konttinen YT. "Tumor necrosis factor-alpha and receptors for it in labial salivary glands in Sjögren's syndrome”. Clin Exp Rheumatol. 2001; 19(2): 131-7.

[17]. Koski H, Janin A, Humphreys-Beher MG, Sorsa T, Malmstrom M and Konttinen YT. "Tumor necrosis factor- $\alpha$ and receptors for it in labial salivary glands in Sjögren's syndrome". Clin Exp Rheumatol. 2004; 19: 131-7.

[18]. Gleissner C, Kaesser U, Dehne F, Bolten W and Willershausen B. " Temporomandibular joint function in patients with longstanding rheumatoid arthritis-I. Role of periodontal status and prosthetic care - a clinical study”. Europ jour of med res.2001; 8: $98-108$

[19]. Goldring SR. "Pathogenesis of bone and cartilage destruction in rheumatoid arthritis". Rheumatol (Oxford),2003; 42 (2): $11-16$.

[20]. Lin Y, Hsu M, Yang J, Liang T, Chou S and Lin H. “ Temporomandibular joint disorders in patients with rheumatoid arthritis”. Jour of the Chin Med Asso. 2007; 70: 527-534.

[21]. Kaomongkolgit R. "Oral lichenoid drug reaction associated with antihypertensive and hypoglycemic drugs". J of Drugs in Dermatol. 2010; 9(1): 73-75.

[22]. Jinbu Y, Kashiwazaki A, Ozawa M, Inoue E, Kusama M and Demitsu T. " Bilateral oral lichenoid lesions on the buccal mucosa due to methotrexate: Report of two cases”. J of Oral and Maxillo Surg,Med\&Patho. 2015; 27(1): 102-105.

[23]. Reamy B, Derby R, Bunt C. "Common tongue conditions in primary care". Amerfam phys. 2010 ; 81 (5): $627-34$.

[24]. Strangfeld, A., \& Listing, J. "Infection and musculoskeletal conditions: Bacterial and opportunistic infections during anti-TNF therapy". Best Pract Res Clin Rheumatol. 2006; 20 (6): 1181-95.

[25]. Park K, Brodell R and Helms S. “Angular cheilitis, part 1: local etiologies”. Cutis. 2011; 87(6): 289-95.

[26]. Ford A and Peyrin-Biroulet L. "Opportunistic infections with anti-tumor necrosis factor-alpha therapy in inflammatory bowel disease: meta-analysis of randomized controlled trials". Am J Gastroenterol.2013; 16: 1268-1276.

[27]. Bishu S, Su E, Wilkerson E, Reckley K, Jones D, McGeachy M and Levesque M. " Rheumatoid arthritis patients exhibit impaired Candida albicans-specific Th17 responses". Arth Res \& Ther. 2014; 16(1): R50.

[28]. Sun, A., Lin, H., Wang, Y., \& Chiang, C. "Significant association of deficiency of hemoglobin, iron and vitamin B12, high homocysteine level, and gastric parietal cell antibody positivity with atrophic glossitis”. J of Oral Patho \& Med. 2012; 41 (6): 500504.

[29]. Plemons J, Al-Hashimi I and Marek C. "Managing xerostomia and salivary gland hypofunction: executive summary of a report from the American Dental Association Council on Scientific Affairs'. J Am Dent Assoc. 2014; 145(8): 867-73.

[30]. Scully C. "Oral and maxillofacial medicine: the basis of diagnosis and treatment" (2nd ed.). Edinburgh: Churchill Livingstone. $2008 ; 356$.

[31]. Abrão, A.L.P., Santana, C.M., Bezerra, A.C.B., de Amorim, R.F.B., da Silva, M.B., da Mota, L.M.H. and Falcão, D.P. "What rheumatologists should know about orofacial manifestations of autoimmune rheumatic diseases". Rev Brasil de Reum (English Edition). 2016 .

[32]. Moen, K., Bertelsen, L., Hellem, S., Jonsson, R., \& Brun, J. "Salivary gland and temporomandibular joint involvement in rheumatoid arthritis: relation to disease activity". Oral dis. 2005; 11: 27-34. 